\title{
Modelo para avaliação da integração ensino- serviço em Unidades Docentes Assistenciais na Atenção Básica
}

\author{
Model for assessment of teaching-service integration in Teaching \\ Service Units in Primary Care
}

José Francisco Gontan Albiero', Sérgio Fernando Torres de Freitas ${ }^{2}$

\begin{abstract}
RESUMO A pesquisa objetivou elaborar um modelo para avaliação da efetividade da integração ensino-serviço na Atenção Básica. O modelo foi elaborado com base na literatura, consulta aos atores envolvidos na integração (gestão, serviço, comunidade e ensino) e técnicas de consenso com discussão de especialistas para validação. O modelo teórico-lógico foi construído com suporte na legislação da saúde e educação. A matriz avaliativa proposta é composta por quatro dimensões e dez indicadores. Posteriormente o modelo proposto será utilizado no intuito de verificar sua aplicabilidade, a necessidade de ajustes e a possibilidade de replicação em diferentes contextos.
\end{abstract}

PALAVRAS-CHAVE Serviços de integração docente-assistencial. Avaliação em saúde. Capacitação de recursos humanos em saúde.

ABSTRACT This research aimed to develop a model for evaluating the effectiveness of the teaching-service integration in Primary Health Care. The model was based on literature, consult with the actors involved in the integration (management, service community and education) and consensus techniques with discussion of experts for validation. The theoretical-logical model was built with support in health and education legislation. The proposed evaluative matrix is composed of four dimensions and ten indicators. Posteriorly, the proposed model will be used to verify its applicability, the need for adjustment and the possibility of replication in different contexts.

KEYWORDS Teaching care integration services. Health evaluation. Human resource training:

${ }^{1}$ Universidade Regional de Blumenau (Furb) Blumenau, (SC), Brasil. chicoalbiero@gmail.com

${ }^{2}$ Universidade Federal de Santa Catarina (UFSC) Florianópolis (SC), Brasil. sergio.freitas@ufsc.br 


\section{Introdução}

As experiências de integração ensino-serviço em saúde no Brasil apresentam tanto avanços nas aproximações institucionais e nas ações em parceria quanto entraves e desafios para sua efetivação (MARSIGLIA, 1995). Nos últimos anos observa-se um movimento de ampliação e fortalecimento da formação em saúde, indutor de mudanças, a partir da aproximação do ensino ao sistema de saúde com o desenvolvimento de múltiplas e novas experiências de integração do ensino com os serviços de saúde (BATISTA ET AL., 2015).

Estudos indicam que a integração ensino-serviço pode favorecer a diminuição da distância entre a formação universitária, a realidade local e necessidades do Sistema Único de Saúde (SUS), ampliando assim o compromisso com seus princípios, permite desenvolver ações e projetos que aproximem objetivos pedagógicos das prioridades locais, e ainda criar sinergias entre os cursos, professores e estudantes que atuam nos serviços (CUNHA; MAGAJEWSKI, 2012; FERLA; FAMER; SANTOS, 2013; SORDI ET AL., 2015). No entanto, outras pesquisas destacam dificuldades neste processo: as diferentes percepções dos atores envolvidos, a indefinição de papéis e a tendência de dominação de um grupo profissional sobre o outro (ANDRADE ET AL., 2014; FLORES ET AL., 2015); interesses institucionais distintos (BECCARIA; TREVIZAN; JANUCCI, 2006; OLSCHOWSKY; SILVA, 2000); dificuldades metodológicas nos processos de trabalho e integração embasada em negociações particulares (ALBUQUERQUE ET AL., 2008; HOLBROOK ET AL., 2008; SORDI ET AL., 2015).

Ao considerar que a integração ensino-serviço no País passa por um processo de ampliação e qualificação e que são encontrados na literatura casos isolados de sua institucionalização como em Porto Alegre, Florianópolis, Fortaleza e Sobral (ellery; BOSI; LOIOLA, 2013; PEREIRA, 2013; REIBNITZ ET AL., 2012) propõe-se um modelo avaliativo das modalidades de integração ensino-serviço para contribuir para esse processo.
A maior parte das experiências descritas de integração ensino-serviço tem similares cenários de práticas - Atenção Básica (AB), em especial nas equipes de Estratégia Saúde da Família (ESF) - porém existem variações tanto nos papéis dos atores quanto nos processos de trabalho realizados.

Em alguns casos ocorre supervisão (presença de docente com os estudantes que estão no cenário) em outros, preceptoria (o profissional do serviço é o responsável por receber os estudantes). Outra diferença pode-se identificar nos processos de trabalho que podem ser compartilhados (grupo da universidade se insere nas ações desenvolvidas pela equipe da unidade) ou próprios (grupo da universidade possui uma agenda de ações em paralelo ao trabalho das equipes do serviço).

Dessa forma configuram-se diferentes tipos de Unidades Docentes Assistenciais (UDA) de acordo com dois elementos de análise: 'orientação' - por supervisão ou preceptoria - e 'processo de trabalho' - compartilhado ou próprio (ALBIERO, 2016)

O objetivo do presente estudo foi elaborar um modelo para a avaliação da efetividade da integração ensino-serviço em diferentes tipos de UDA na AB.

\section{Metodologia}

Trata-se de uma pesquisa metodológica de abordagem qualitativa, para elaborar um modelo de avaliação para a integração ensino-serviço, nos diferentes tipos de UDA (SCARATTI; CALVO, 2012).

A pesquisa foi realizada por meio de três estratégias: revisão de literatura; entrevistas com atores envolvidos com a integração ensino-serviço (gestão, serviço, comunidade e ensino) e técnicas de consenso com consulta a especialistas para definição e validação das dimensões e indicadores de avaliação.

Para o levantamento bibliográfico foram consultadas as bases de dados da Biblioteca 
Virtual em Saúde (BVS), composta por: Literatura Latino-Americana e do Caribe em Ciências da Saúde (Lilacs), Índice Bibliográfico Español de Ciencias de la Salud (Ibecs), Sistema Online de Busca e Análise de Literatura Médica (Medline), Biblioteca Cochrane e Scientific Electronic Library Online (SciELO). Foram empregados os descritores de serviços de integração docente assistencial em inglês, espanhol e português: teaching integration services/servicios integración docente asistencial, integração ensino serviço e ensino em serviço. Esta etapa permitiu a identificação preliminar de indicadores e apoiou a elaboração do modelo teórico-lógico.

A opção metodológica de consultar os envolvidos é baseada nas concepções de Furtado (2001) que propõe um método construtivista/ participativo para avaliação em saúde, em que o engajamento dos atores, contribui para a reflexão de suas práticas, possibilita aos envolvidos a coparticipação, o comprometimento e o uso da avaliação realizada.

Esta etapa da pesquisa foi realizada em um município de Santa Catarina com 28 atores da integração ensino-serviço assim distribuídos: quatro participantes da gestão (dois do Núcleo de Educação Permanente, a coordenação da educação e trabalho do município e a coordenação da $\mathrm{AB}$ ); oito docentes da área da saúde da universidade com, no mínimo, um ano de atividades de ensino e/ou extensão nas unidades de saúde do município; oito discentes da mesma universidade que atuam em estágio ou projeto de extensão nas unidades; quatro coordenadores de Unidades Básicas de Saúde (UBS) com histórico de maior antiguidade atuando com a integração ensino-serviço e quatro usuários das mesmas unidades com participação ativa nas rotinas do bairro e/ou representante do Conselho Local de Saúde (CLS).

Foi construído um instrumento de coleta de dados composto por duas partes: uma entrevista e um questionário auto preenchido.

A entrevista foi composta por três questões abertas que visavam conhecer, na perspectiva do entrevistado, as concepções, potencialidades, desafios e indicadores de efetividade para a integração ensino-serviço. As entrevistas foram trabalhadas por meio da técnica de análise de conteúdo, visando identificar e categorizar os indicadores citados pelos participantes. O questionário foi aplicado após a entrevista, sendo composto por uma lista de nove indicadores de avaliação da integração ensino-serviço identificado na literatura ao longo do processo de construção deste estudo. Os respondentes deveriam indicar segundo sua concepção, o grau de importância desses indicadores, em máximo, médio ou mínimo.

A terceira etapa possibilitou o debate e a validação dos indicadores identificados. Os dados foram analisados, organizados e submetidos à discussão com especialistas, sob forma de comitê tradicional (BERETTA; CALVO; LACERDA, 2011), com a finalidade de fortalecer a validade interna do estudo e ainda discutir sobre dimensões, indicadores, medidas e parâmetros da matriz avaliativa proposta. $\mathrm{O}$ comitê tradicional foi realizado em dois municípios de Santa Catarina e o grupo de debatedores foi composto por dois representantes da gestão (diretor (a) da $\mathrm{AB}$ e integrador (a) ensino-serviço de cada município), dois professores e dois estudantes com experiência de integração, dois profissionais do serviço e dois usuários do CLS de unidades com histórico de integração e três especialistas em avaliação em saúde.

Ao final de todo processo foi proposta matriz avaliativa que será apresentada na sequência neste manuscrito (Certificado de Apresentação para Apreciação Ética - CAAE $\mathrm{n}^{\circ}$ 38418314.0.0000.5361. Parecer $\mathrm{n}^{\circ}$ 988.520. Instituição proponente: Universidade Federal de Santa Catarina).

\section{Resultados}

O Modelo Teórico Lógico (MTL) é o primeiro resultado do estudo e foi composto por duas partes. A parte teórica tem origem nas políticas de educação permanente do Ministério da Saúde e nas políticas de formação do Ministério 
da Educação que em ambos os 'braços' convergem para a integração ensino-serviço, neste caso ela se configura como elemento de ligação entre as políticas. Na parte lógica do modelo apresentam-se os envolvidos e assume-se o que pode ser considerado como efetividade da integração ensino-serviço.

Neste estudo adotou-se o critério da efetividade, entendido como capacidade real para responder às exigências sociais e demandas políticas da comunidade envolvida (SANDER, 1995).

Figura 1. Modelo Teórico-Lógico para avaliação da efetividade da integração ensino-serviço na Atenção Básica

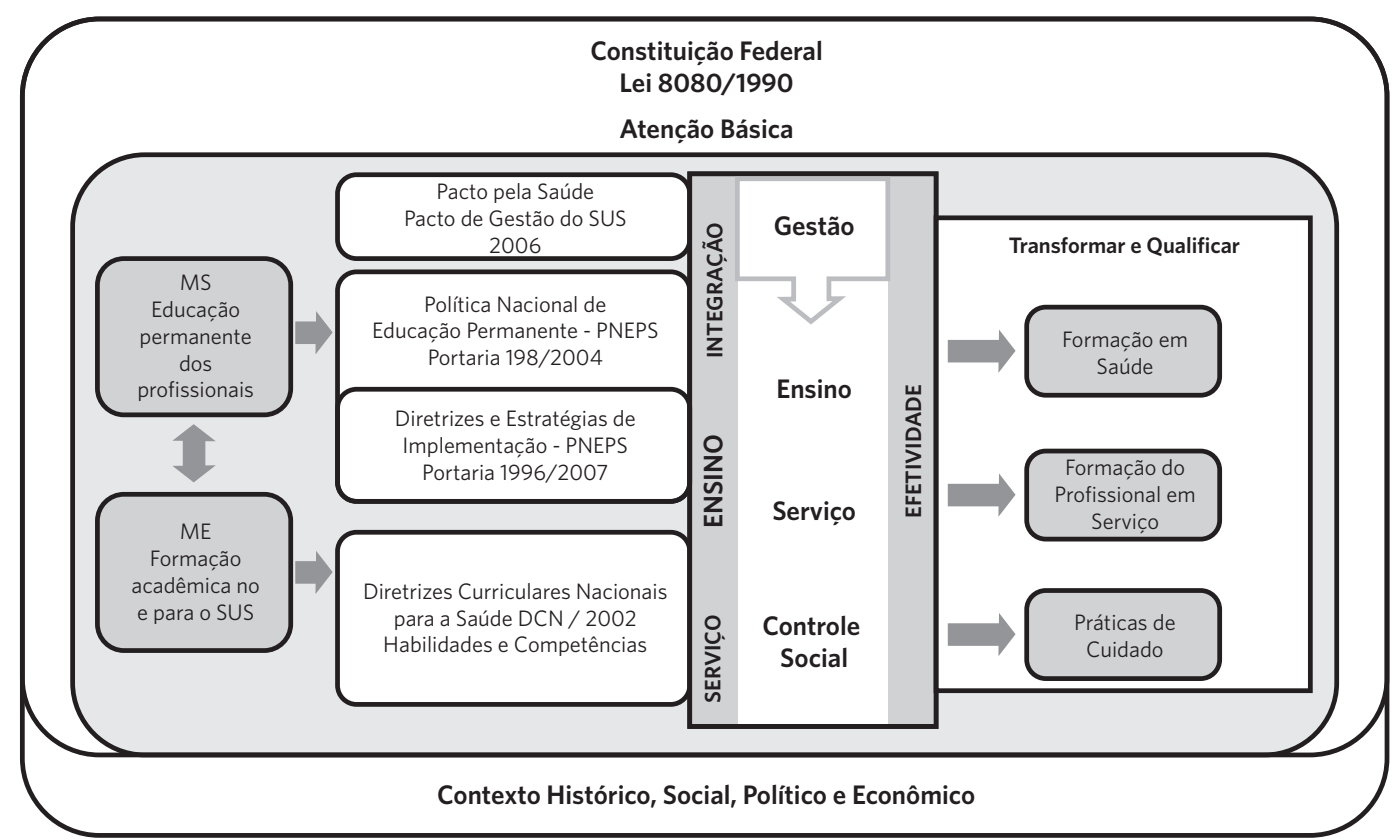

Segundo o MTL a integração ensino-serviço será efetiva quando contribuir para a transformação e qualificação da formação em saúde; da formação em serviço; e das práticas de cuidado.

\section{As dimensões}

As quatro dimensões que compõem a matriz avaliativa foram definidas e respaldadas em legislação e revisão de literatura. Tanto na Política Nacional de Educação Permanente (PNEPS) (BRASIL, 2004) quanto nas suas Diretrizes e Estratégias de Implementação (BRASIL, 2007) ficam estabelecidos quatro segmentos intrinsecamente envolvidos no processo da integração ensino-serviço:
[...] Instituição de relações orgânicas e permanentes entre as estruturas de gestão da saúde, as instituições de ensino, os órgãos de controle social em saúde e as ações e os serviços de atenção à saúde [...]. (BRASIL, 2004, P. 8).

Além disso, autores como Ceccim e Feuerwerker (2004), Albuquerque et al. (2008), Brehmer e Ramos (2014), Marin et al. (2014) sustentam que o processo de formação, educação permanente e integração ensino-serviço são constituídos por quatro segmentos que se comunicam e relacionam integralmente.

Neste sentido, foram definidas como dimensões para o estudo: Gestão, Serviço, Comunidade e Ensino sendo relacionados indicadores correspondentes para cada dimensão, descritos a seguir. 


\section{Os indicadores}

Os indicadores de avaliação para a integração ensino-serviço identificados nos discursos dos participantes estavam presentes na literatura especializada evidenciando concordância entre os envolvidos com a integração e os autores que estudam o tema. Os indicadores de avaliação estão apresentados no quadro 1.

Quadro 1. Indicadores para avaliação da efetividade da integração ensino-serviço identificados na literatura e respectivos autores de referência

\begin{tabular}{|c|c|}
\hline Indicador & Autor(es) de Referência \\
\hline Satisfação do usuário & $\begin{array}{l}\text { Mendez (2012); Moimaz, Marques e Saliba (2010); Kuabara et al. } \\
\text { (2014); Brehmer e Ramos (2014) }\end{array}$ \\
\hline $\begin{array}{l}\text { Motivação dos profissionais para desenvolvimen- } \\
\text { to do trabalho em equipe }\end{array}$ & Brehmer e Ramos (2014); Reibnitz et al. (2012); Marin et al. (2014) \\
\hline $\begin{array}{l}\text { Ampliar o conceito de saúde e conhecimento do } \\
\text { SUS na rotina dos acadêmicos }\end{array}$ & $\begin{array}{l}\text { Kuabara et al. (2014); Brehmer e Ramos (2014); Ferla, Famer e San- } \\
\text { tos (2013); Flores et al. (2015); Dalmolin et al. (2011); Câmara et al. } \\
\text { (2012) }\end{array}$ \\
\hline $\begin{array}{l}\text { Aumentar o acesso (número de atendimentos à } \\
\text { comunidade) }\end{array}$ & Tombini (2010); Pereira e Fracolly (2011) \\
\hline Atualizar e reformular os currículos universitários & $\begin{array}{l}\text { Brehmer e Ramos (2014); Reibnitz et al. (2012); Albuquerque et al. } \\
\text { (2008); Castro et al. (2012); Cavalheiro e Guimarães (2011); Fuentes } \\
\text { e Garcia (2011); Souza e Carceri (2011) }\end{array}$ \\
\hline Resolubilidade da Atenção Básica & $\begin{array}{l}\text { Gonçalves et al. (2011); Pizzinato et al. (2012); Caetano Diniz e Soa- } \\
\text { res (2009) }\end{array}$ \\
\hline Fortalecer o controle social & Queiroz et al. (2015); Paim (2009); Ferreira et al. (2012) \\
\hline $\begin{array}{l}\text { Aumentar e manter a frequência aos grupos } \\
\text { educativos }\end{array}$ & Caetano Diniz e Soares (2009); Feurerwerker e Sena (2002) \\
\hline $\begin{array}{l}\text { Aperfeiçoamento profissional/formação em ser- } \\
\text { viço (ampliação dos currículos dos profissionais) }\end{array}$ & $\begin{array}{l}\text { Ferla et al. (2013); Pizzinato et al. (2012); Lima e Rozendo (2015); } \\
\text { Ceccim (2005) }\end{array}$ \\
\hline
\end{tabular}

No quadro 2 estão sistematizadas as quatro indicadores e medidas. dimensões estabelecidas, seus respectivos

Quadro 2. Dimensões, indicadores e medidas da matriz avaliativa para avaliação da integração ensino-serviço da Atenção Básica

\begin{tabular}{lll}
\hline Dimensão & Indicador & Medida \\
\hline Gestão & 1 Ampliação do Acesso & Razão entre o número de procedimentos individuais e coletivos realizados na \\
& & unidade e a população cadastrada em meses letivos e não letivos \\
& 2 Resolubilidade Atenção & Razão entre o número de encaminhamentos da unidade e número de consul- \\
& Básica & tas médicas em meses letivos e não letivos \\
Serviço & 3 Motivação para traba- & Escala do tipo Likert aplicada aos profissionais das equipes das UDA partici- \\
& lho em equipe & pantes com resultados distribuídos em 3 extratos: 25\% com maior motiva- \\
& & ção - 50\% com motivação intermediária - 25\% com menor motivação. \\
\hline
\end{tabular}




\begin{tabular}{|c|c|c|}
\hline \multicolumn{3}{|c|}{ Quadro 2. (cont.) } \\
\hline \multirow[t]{2}{*}{ Serviço } & $\begin{array}{l}4 \text { Aperfeiçoamento } \\
\text { profissional }\end{array}$ & $\begin{array}{l}\text { Cursos de aperfeiçoamento (carga horária igual ou maior que 180h) - 1,0 } \\
\text { ponto; especializações (carga horária igual ou maior que } 360 \text { h) - 0,5 ponto; } \\
\text { outras atividades opcionais de educação permanente (carga horária inferior } \\
\text { a 180h) - 0,5 ponto que tenham sido realizados por médico (a) e enfermeiro } \\
\text { (a) após seu ingresso na Atenção Básica do município. }\end{array}$ \\
\hline & $\begin{array}{l}5 \text { Frequência a grupos } \\
\text { (atividades coletivas) }\end{array}$ & $\begin{array}{l}\text { Taxa de frequência mensal ao grupo por número de cadastrados em meses } \\
\text { letivos e não letivos }\end{array}$ \\
\hline \multirow[t]{2}{*}{$\begin{array}{l}\text { Comuni- } \\
\text { dade }\end{array}$} & 6 Satisfação do usuário & $\begin{array}{l}\text { Escala do tipo Likert aplicada aos líderes da comunidade e/ou representan- } \\
\text { tes do conselho local com resultados distribuídos em } 3 \text { extratos: } 25 \% \text { dos } \\
\text { maiores índices de satisfação - 50\% dos índices intermediários - 25\% dos } \\
\text { menores índices de satisfação. }\end{array}$ \\
\hline & $\begin{array}{l}7 \text { Fortalecimento contro- } \\
\text { le social }\end{array}$ & $\begin{array}{l}\text { Escala do tipo Likert aplicada aos líderes da comunidade e/ou representan- } \\
\text { tes do conselho local com resultados distribuídos em } 3 \text { extratos: } 25 \% \text { com } \\
\text { maiores índices de concordância - 50\% índices intermediários - 25\% com } \\
\text { menores índices de concordância. }\end{array}$ \\
\hline \multirow[t]{3}{*}{ Ensino } & $\begin{array}{l}8 \text { Ampliação conceito de } \\
\text { saúde }\end{array}$ & $\begin{array}{l}\text { Escala do tipo Likert aplicada aos estudantes e professores que atuam nas } \\
\text { UDA participantes com resultados distribuídos em } 3 \text { extratos: 25\% com } \\
\text { maiores índices de concordância - 50\% índices intermediários - 25\% com } \\
\text { menores índices de concordância. }\end{array}$ \\
\hline & $\begin{array}{l}9 \text { Ampliação conheci- } \\
\text { mento SUS }\end{array}$ & $\begin{array}{l}\text { Escala do tipo Likert aplicada aos estudantes e professores que atuam nas } \\
\text { UDA participantes com resultados distribuídos em } 3 \text { extratos: } 25 \% \text { com } \\
\text { maiores índices de concordância - 50\% índices intermediários - } 25 \% \text { com } \\
\text { menores índices de concordância. }\end{array}$ \\
\hline & $\begin{array}{l}10 \text { Adequações curri- } \\
\text { culares }\end{array}$ & $\begin{array}{l}\text { Existência de adequações curriculares nos últimos cinco anos com amplia- } \\
\text { ção de disciplinas e/ou cargas horárias relativas ao SUS; e presença de ligas, } \\
\text { núcleos, programas de extensão relacionados ao SUS nos cursos avaliados. } \\
\text { Para cada resposta sim 1,0 ponto/para cada resposta não zero ponto. }\end{array}$ \\
\hline
\end{tabular}

\section{INDICADOR 1: AMPLIAC̣ÃO DO ACESSO}

A presença de estudantes e professores nas unidades de saúde pode ampliar a cobertura de assistência tanto em ações individuais quanto nas ações coletivas em grupos de educação em saúde. O planejamento do trabalho integrado da equipe com comunidade acadêmica poderá resultar em disponibilidade e velocidade de ação (TOMBINI, 2010; PEREIRA; FRACOLLI, 2011).

$\mathrm{O}$ indicador identifica em quais tipos de UDA existe maior acesso da comunidade, bem como se há diferença de acesso em períodos letivos e não letivos do ano. É calculado por uma razão entre o número de procedimentos individuais e coletivos realizados na unidade e a população cadastrada em meses letivos - abril e setembro, e não letivos - fevereiro e julho. Os meses são escolhidos intencionalmente (utilizados nos indicadores 1, 2 e 5), em função de serem considerados típicos, mais estáveis para as atividades em campo. Em março e agosto, por exemplo, de acordo com calendário acadêmico existem semanas de organização das atividades de campo ainda em ambiente universitário, diminuindo assim os dias das ações junto às UBS.

\section{INDICADOR 2: RESOLUBILIDADE DA AB}

Caetano, Diniz e Soares (2009), Gonçalves; Albiero (2011) e Pizzinato et al. (2012) destacam maior satisfação dos usuários com os serviços nos locais em que a universidade está presente, explicada pelo aumento de acesso a consultas, ampliação da participação da comunidade nas ações das unidades, menores índices de encaminhamentos para atenção especializada e, em muitos casos, serviços prestados em equipe multiprofissional. 
Nesta situação amplia-se o número de casos resolvidos na UBS e refina-se a condução para os demais níveis de atenção.

Este indicador identifica em quais tipos de UDA existe maior índice de resolubilidade, aqui definido pelas menores taxas de encaminhamentos para setores especializados da rede, observadas as variações de resolubilidade em períodos letivos e não letivos. Calculado por uma razão entre o número de encaminhamentos da unidade e número de consultas médicas nos meses selecionados.

\section{INDICADOR 3: MOTIVAC̣ÃO PARA TRABALHO EM EQUIPE}

A aproximação entre ensino e serviço possibilita aos docentes e aos trabalhadores dos serviços de saúde a educação permanente, sendo uma via dupla para o frequente intercâmbio de conhecimento. Os atores envolvidos no processo sentem-se motivados em vivenciar o trabalho em equipe e perceber in loco as repercussões e parcerias com a comunidade. Nesse sentido, a valorização do trabalho em equipe pode ser identificada como importante indicador de desempenho profissional (BREHMER; RAMOS, 2014; MARIN ET AL., 2014; NUNES, 2002; REIBNITZ, 2012; VIEIRA ET AL., 2017).

Indicador que identifica em quais tipos de UDA existe maior motivação para realizar seu trabalho em equipe. Uma escala do tipo Likert - 'Você se sente motivado para trabalhar nesta unidade? Para trabalhar em equipe multiprofissional? Para desenvolver atividades em parceria com a universidade?' - é aplicada aos profissionais das equipes selecionadas para a avaliação.

No intuito de realizar a avaliação usando como referência as próprias UDA selecionadas optou-se por distribuir os resultados em três extratos de acordo com as pontuações obtidas: 1) $25 \%$ das UDA participantes com maior motivação; 2) 50\% das UDA participantes com motivação intermediária e 3) $25 \%$ das UDA participantes com menor motivação. Dessa forma o passo seguinte
- ajuizamento de valor - fica facilitado para atribuição de pontos em cada extrato. Esta lógica avaliativa é utilizada também nos indicadores 6, 7, 8 e 9.

\section{INDICADOR 4: APERFEIÇOAMENTO PROFISSIONAL}

A participação em diferentes tipos de ações e programas na comunidade universitária pode levar a maior qualificação e aprimoramento técnico dos trabalhadores. A convivência com docentes e discentes e a proximidade da universidade podem gerar nos profissionais o desejo de buscar aprimoramentos inclusive especializações (FERLA; FAMER; SANTOS, 2013; LIMA; ROSENDO, 2015; PIZZINATO ET AL., 2012)

Indicador que identifica em quais tipos de UDA os profissionais apresentam maiores índices de aperfeiçoamento profissional. São pontuados: cursos de aperfeiçoamento (carga horária igual ou maior que 180h); especializações (carga horária igual ou maior que 360h); outras atividades opcionais de educação permanente (carga horária inferior a 180h) que tenham sido realizados por médico(a) e enfermeiro(a) após seu ingresso na $\mathrm{AB}$ do município.

$\mathrm{Na}$ oficina de consenso com especialistas foi definido que os cursos de aperfeiçoamento teriam maior pontuação em função de não significarem compensações econômicas (progressão na carreira) para o trabalhador, ou seja, sugere que a disposição de se atualizar é o motivo principal da busca dessa formação. Para cursos de aperfeiçoamento foi atribuído 1,0 ponto. As demais atividades 0,5 pontos para cada.

\section{INDICADOR 5: FREQUÊNCIA A GRUPOS (ATIVIDADES COLETIVAS)}

Caetano, Diniz e Soares (2009) e Feuerwerker e Sena (2002) destacam as repercussões da educação permanente e do ensino em serviço na qualidade dos atendimentos prestados à comunidade tanto individual quanto 
coletivamente. Neste sentido, a integração estimula a maior participação popular e a busca pela integralidade e resolubilidade adequadas a realidade local.

Indicador que identifica quais tipos de UDA apresentam maior participação nas atividades coletivas (grupos) desenvolvidos nas unidades selecionadas. Calculado por uma taxa de frequência mensal ao grupo por número de cadastrados.

Foi selecionado o grupo de hipertensos e diabéticos (conhecidos na $\mathrm{AB}$ como grupo de Hiperdia) em função de ser o mais frequente nas unidades, os meses foram escolhidos intencionalmente, em função de serem considerados típicos, mais estáveis para as atividades em campo, e foram justificados anteriormente no indicador 1.

\section{INDICADOR 6: SATISFAC̣ÃO DO USUÁRIO}

Moimaz, Marques e Saliba (2010) evidenciam que o usuário é o ponto central dos processos de avaliação, e que o diálogo permanente entre profissionais e população local pode ser responsável por modificar e qualificar o cotidiano das práticas e o próprio sistema.

Para Brandão, Giovanella e Campos (2013) avaliar a satisfação dos usuários é ferramenta fundamental para subsidiar decisões compartilhadas, práticas profissionais, reorganizar processos de trabalho bem como realocar recursos, readequar ações e redefinir objetivos.

Nesta lógica, trabalhos em parceria do serviço com a universidade podem contribuir tanto para a satisfação da comunidade quanto para seu empoderamento nas práticas preventivas de saúde (BREHMER; RAMOS, 2014; KUABARA ET AL., 2014; MÈNDEZ, 2012).

Indicador que identifica em quais tipos de UDA existe maior satisfação do usuário com a assistência prestada nas unidades Uma escala do tipo Likert - 'Você está satisfeito com o atendimento nesta unidade? Com o acolhimento dos profissionais? Com o contato com professores e alunos da universidade?' - é aplicada aos líderes da comunidade e/ou participantes dos CLS das UDA selecionadas e os resultados obtidos serão distribuídos em três extratos conforme descrito anteriormente: 1) $25 \%$ das UDA participantes com maiores índices de satisfação; 2) $50 \%$ das UDA participantes com índices intermediários e 3) $25 \%$ das UDA com menores índices de satisfação.

\section{INDICADOR 7: FORTALECIMENTO DO CONTROLE SOCIAL}

Queiroz et al. (2015), Ferreira, Forster e Santos (2012) e Paim (2009) sustentam que a participação da comunidade expressa a orientação para democratizar os serviços e as decisões em relação à saúde da comunidade. Nas unidades de saúde com presença da universidade tem-se a expectativa de que a comunidade seja estimulada a participar com maior número de pessoas destacando dessa forma o seu direito de decidir democraticamente sobre as necessidades e prioridades de seu território.

Indicador que identifica em quais tipos de UDA existe maior estímulo para o fortalecimento do controle social. Uma escala do tipo Likert - 'A comunidade melhorou sua participação e interesse. Conselho Local está atuante' - é aplicada aos líderes da comunidade e/ou participantes dos CLS das UDA selecionadas e os resultados obtidos serão distribuídos em três extratos conforme descrito anteriormente: 1$) 25 \%$ das UDA participantes com maiores índices de concordância; 2) 50\% das UDA participantes com índices intermediários e 3) 25\% das UDA participantes com menores índices de concordância.

\section{INDICADOR 8: AMPLIAÇÃO DO CONCEITO DE SAÚDE NOS ENVOLVIDOS}

Há necessidade de formação permanente e exercício contínuo no cotidiano das UBS para que o conceito ampliado de saúde seja incorporado por todos e de fato, estabeleça novas práticas e novos processos de trabalho 
(CÂMARA ET AL., 2012; DALMOLIM ET AL., 2011; FERLA; FAMER;

SANTOS, 2013; RIBEIRO, 2013;).

Indicador que identifica em quais tipos de UDA existe maior ampliação do conceito de saúde nos acadêmicos e professores envolvidos na integração ensino-serviço. Uma escala do tipo Likert - 'Eu conheço o conceito ampliado de saúde. Eu vivenciei na prática este conceito. Conceito ampliado de saúde é o meu conceito de saúde' é aplicada aos acadêmicos e professores que atuam nas UDA selecionadas e os resultados obtidos são distribuídos em três extratos conforme descrito anteriormente: 1) $25 \%$ das UDA participantes com maiores índices de concordância; 2) 50\% das UDA participantes com índices intermediários e 3) $25 \%$ das UDA participantes com menores índices de concordância.

\section{INDICADOR 9: AMPLIAC̣ÃO DO CONHECIMENTO SOBRE O SUS}

Pesquisas recentes como as de Kuabara et al. (2014), Brehmer e Ramos (2014), Flores et al. (2015) identificam que além da articulação teoria e prática e uma formação mais humanizada e inserida na realidade local, o ensino em serviço amplia o conhecimento do SUS e a proximidade dos alunos da saúde coletiva.

Indicador que identifica em quais tipos de UDA existe maior ampliação do conhecimento sobre o SUS nos acadêmicos e professores envolvidos na integração ensino-serviço. Uma escala do tipo Likert - 'Conheço os princípios do SUS. Os vejo colocados em prática. Consigo relacionar o SUS com outras disciplinas' - é aplicada aos acadêmicos e professores que atuam nas UDA selecionadas e os resultados obtidos serão distribuídos em três extratos conforme descrito anteriormente: 1) $25 \%$ das UDA participantes com maiores índices de concordância; 2) 50\% das UDA participantes com índices intermediários e 3) 25\% das UDA participantes com menores índices de concordância.

\section{INDICADOR 10: ADEQUAC̣ÕES CURRICULARES}

Muitos estudos como os de Cavalheiro e Guimarães (2011), Albuquerque et al. (2008), Souza e Carcereri (2011), Fuentes e Garcia (2011), Castro, Braga e Freires (2012), Reibnitz et al. (2012), Brehmer e Ramos (2014) destacam a integração ensino serviço como potencial estratégia colaboradora do processo de mudanças na formação em saúde e ainda que a aprendizagem nos serviços potencializa o desenvolvimento curricular.

Indicador que busca identificar quais tipos de UDA podem estimular ajustes e adequações curriculares que visem enfatizar a saúde e o SUS ao longo da graduação. Indicador composto por duas medidas, com respostas Sim/Não, sendo atribuído um ponto para o sim e zero ponto para o não. São utilizadas duas medidas: existência de adequações curriculares nos últimos cinco anos com ampliação de disciplinas e/ou cargas horárias relativas ao SUS; e presença de ligas, núcleos, programas de extensão relacionados ao SUS nos cursos avaliados. Para cada resposta sim nas duas medidas se atribui 1 ponto.

\section{JULGAMENTOS DE CADA DIMENSÃO}

As dimensões foram julgadas a partir da soma de pontos dos indicadores, recebendo conceito Bom, Regular, ou Ruim, de acordo com as pontuações atingidas.

Na dimensão 1 (Gestão) cada UDA poderá atingir 4 pontos. Será considerada Ruim a UDA que não pontuar; Regular a que pontuar 1 ou 2 pontos e Boa a que pontuar 3 ou 4 pontos.

Na dimensão 2 (Serviço) cada UDA poderá atingir 6 pontos. Será considerada Ruim a UDA que fizer até 1 ponto; Regular a que pontuar 2 a 4 pontos e Boa a que pontuar 5 ou 6 pontos.

Na dimensão 3 (Comunidade) cada UDA 
poderá atingir 5 pontos. Será considerada Ruim a UDA que fizer até 1 ponto; Regular a que fizer 2 pontos e Boa a que pontuar 3 a 5 pontos.

Na dimensão 4 (Ensino) cada UDA poderá atingir 6 pontos. Será considerada Ruim a
UDA que fizer até 1 ponto; Regular a que fizer 2 a 4 pontos e Boa a que pontuar 5 e 6 pontos. Por fim o juízo de valor sobre o tipo de UDA e o favorecimento a integração ensino serviço apresentado no quadro 3:

Entende-se que para uma UDA favorecer

Quadro 3. Julgamento das dimensões e ajuizamento de valor para a avaliação da efetividade da integração ensino-serviço na Atenção Básica

\begin{tabular}{|c|c|c|}
\hline Dimensão & Julgamento da dimensão & Pontuação por atributo da dimensão \\
\hline D1 Gestão & $\begin{array}{l}0 \text { pontos = Ruim } \\
1 \text { e } 2 \text { pontos }=\text { Regular } \\
3 \text { e } 4 \text { pontos }=\text { Bom }\end{array}$ & $\begin{array}{l}\text { Ruim }=0 \text { pontos } \\
\text { Regular }=1 \text { ponto } \\
\text { Bom }=2 \text { pontos }\end{array}$ \\
\hline D2 Serviço & $\begin{array}{l}0 \text { e } 1 \text { ponto }=\text { Ruim } \\
2 \text { a } 4 \text { pontos }=\text { Regular } \\
5 \text { e } 6 \text { pontos }=\text { Bom }\end{array}$ & $\begin{array}{l}\text { Ruim }=0 \text { pontos } \\
\text { Regular }=1 \text { ponto } \\
\text { Bom }=2 \text { pontos }\end{array}$ \\
\hline D3 Comunidade & $\begin{array}{l}0 \text { e } 1 \text { ponto = Ruim } \\
2 \text { pontos = Regular } \\
3 \text { a } 5 \text { pontos }=\text { Bom }\end{array}$ & $\begin{array}{l}\text { Ruim }=0 \text { pontos } \\
\text { Regular }=1 \text { ponto } \\
\text { Bom }=2 \text { pontos }\end{array}$ \\
\hline D4 Ensino & $\begin{array}{l}0 \text { e } 1 \text { ponto }=\text { Ruim } \\
2 \text { a } 4 \text { pontos }=\text { Regular } \\
5 \text { e } 6 \text { pontos }=\text { Bom }\end{array}$ & $\begin{array}{l}\text { Ruim }=0 \text { pontos } \\
\text { Regular }=1 \text { ponto } \\
\text { Bom }=2 \text { pontos }\end{array}$ \\
\hline \multicolumn{3}{|c|}{ Ajuizamento de Valor - Somatória de Pontos FINAL } \\
\hline $\begin{array}{l}\text { Efetivo } \\
6 \text { a } 8 \text { pontos }\end{array}$ & $\begin{array}{l}\text { Parcialmente efetivo } \\
4 \text { ou } 5 \text { pontos }\end{array}$ & $\begin{array}{l}\text { Não efetivo } \\
0 \text { a } 3 \text { pontos }\end{array}$ \\
\hline $\begin{array}{l}\text { Sem a possibilidade de ser ruim nas } \\
\text { dimensões } 2 \text { (serviço), } 3 \text { (comunida- } \\
\text { de) e } 4 \text { (Ensino) }\end{array}$ & $\begin{array}{l}\text { Sem a possibilidade de ser ruim nas } \\
\text { dimensões } 2 \text { (serviço), } 3 \text { (comunida- } \\
\text { de) e } 4 \text { (Ensino) }\end{array}$ & \\
\hline
\end{tabular}

a efetividade da integração ensino-serviço, seja total ou parcialmente, não pode ter atributo 'Ruim' nas dimensões ensino, serviço e comunidade. A gestão é função 'meio', aquela que vai garantir e sustentar as inter-relações das funções 'fim'; por isso, considera-se que uma UDA foi bem avaliada nas atividades fim, ainda que esteja ruim na atividade meio, ainda tem possibilidades de ser bem avaliada no que diz respeito à efetividade do desenvolvimento das ações de integração ensino serviço.

\section{Discussão}

A dimensão ‘Gestão' utilizou dois indicadores: ampliação do acesso e da resolubilidade da AB. Argumenta-se que uma UDA com trabalho integrado possa apresentar maior oferta de serviços - seja na amplitude de ações, seja na sua quantidade, maiores possibilidades de discussão e ação sobre os casos da comunidade e ainda a ampliação de ações coletivas de educação em saúde. 
A função da gestão se baseia fundamentalmente na busca da melhoria da atenção prestada e do nível de saúde da população assistida. Um grande desafio em qualquer país, especialmente nos de baixa e média renda é ampliar a coerência entre os recursos disponíveis, os serviços e as necessidades da comunidade. Dessa forma, organizar e ofertar serviços em quê estão as necessidades, ampliar acesso à rede de serviços, potencializar a resolubilidade da atenção e a satisfação dos usuários são objetivos importantes (DUSSALT, 1992).

Nesta lógica, estudos sobre a integração ensino-serviço indicam maior satisfação de usuários com serviços nos locais em que a universidade está presente. Ademais justificam pelo aumento de vagas em consultas, diversidade na oferta de serviços, ampliação da participação da comunidade nas ações das unidades, menores índices de referência para o serviço especializado e, em muitos casos, serviços prestados em equipe multiprofissional (GONÇALVES; ALBIERO, 2011; PIZZINATO ET AL., 2012)

A dimensão 'Serviço' tem como indicadores: motivação para trabalho em equipe; aperfeiçoamento profissional e aumento da frequência as atividades coletivas da unidade. Neste sentido, estes três indicadores sugerem um encadeamento. Se o trabalho parceiro com docentes e discentes inspira e amplia a motivação dos trabalhadores em serviço, tem-se a expectativa do aprimoramento ser permanente e, por conseguinte refletir na qualificação de todas as ações realizadas na unidade.

A aproximação entre ensino e serviço possibilita aos docentes e aos trabalhadores dos serviços de saúde a educação permanente, sendo uma via dupla para o frequente intercâmbio de conhecimento. Desta maneira, os atores envolvidos no processo sentem-se motivados em estar vivenciando o trabalho em equipe e percebendo in loco as repercussões e parcerias com a comunidade (BREHMER; RAMOS, 2014; REIBNITZ ET AL., 2012).

A participação em diferentes tipos de ações e programas na comunidade universitária tem servido como estímulo a qualificação e aprimoramento técnico dos trabalhadores. A convivência com docentes e discentes e a proximidade da universidade podem gerar nos profissionais o desejo de buscar aprimoramentos inclusive especializações (LIMA; ROSENDO, 2015; PIZZINATO ET AL., 2012). Caetano Diniz e Soares (2009) e Feuerwerker e Sena (2002) destacam as repercussões da educação permanente e do ensino em serviço na qualidade dos atendimentos prestados à comunidade tanto individual quanto coletivamente.

A dimensão 'Comunidade' é composta por dois indicadores: a satisfação do usuário e o fortalecimento do controle social. Moimaz, Marques e Saliba (2010) evidenciam que o usuário é o ponto central dos processos de avaliação e ainda que a diálogo permanente entre profissionais e população local pode ser responsável por modificar e qualificar o cotidiano das práticas e o próprio sistema. Uma UDA com trabalho conjunto e integrado acaba por ampliar suas ações e sua aproximação da comunidade. Desta forma pode significar maior satisfação do usuário e ainda o empoderamento e qualificação da participação popular. Queiroz et al. (2015) e Paim (2009) sustentam que a participação da comunidade expressa a orientação para democratizar os serviços e as decisões em relação à saúde da comunidade.

A dimensão 'Ensino' possui três indicadores: ampliação do conceito de saúde e do conhecimento do SUS e adequações curriculares. A presença de docentes e discentes no cotidiano das unidades e a realização de ações integradas no serviço e na comunidade podem consolidar a apropriação do conceito de saúde para além de ausência de queixas e ainda a visualização rotineira tanto da filosofia do SUS e seus desafios. Por conseguinte estas experiências e pessoas acabam por retornar à universidade dispostas a qualificar sua formação de forma permanente.

Há necessidade de formação permanente 
e exercício contínuo no cotidiano das UBS para que o conceito ampliado de saúde seja incorporado por todos e de fato, estabeleça novas práticas e novos processos de trabalho (CÂMARA ET AL. 2012; DALMOLIM ET AL. 2011).

Pesquisa recente como a de Flores et al. (2015) identifica que além da articulação teoria e prática e uma formação mais humanizada e inserida na realidade local, o ensino em serviço amplia o conhecimento do SUS e a proximidade dos alunos da saúde coletiva. Muitos estudos como os de Cavalheiro e Guimarães (2011), Albuquerque et al. (2008), Souza e Carcereri (2011), Fuentes e Garcia (2011), Castro et al. (2012), Reibnitz et al. (2012), Brehmer e Ramos (2014) destacam a integração ensino serviço como potencial estratégia colaboradora do processo de mudanças na formação em saúde e ainda que a aprendizagem nos serviços potencializa o desenvolvimento curricular.

\section{Considerações finais}

A construção do modelo de avaliação da integração ensino-serviço para $\mathrm{AB}$ foi realizada em um processo composto por três momentos distintos, porém complementares: a revisão e atualização de literatura especializada, a consulta aos atores envolvidos no processo de integração (Gestão, Serviço, Comunidade e Ensino) e as oficinas de consenso e discussão entre especialistas da área de avaliação e representantes dos grupos mencionados anteriormente.

A matriz proposta possui quatro dimensões, dez indicadores e dez medidas visando identificar quais os tipos de UDA mais ou menos favorecem a efetividade da integração ensino-serviço.

$\mathrm{O}$ modelo avaliativo será testado em um município com histórico de integração ensino-serviço para verificar sua aplicabilidade, a necessidade de adequações e ajustes, suas limitações e a possibilidade de ser utilizada em diferentes contextos e em maior escala.

Ao considerar o momento atual do País em que o SUS é ameaçado em todos os seus fundamentos e diretrizes, identificar e avaliar um de seus grandes papéis - ser escola, contribuir na formação de novos profissionais e investir na formação permanente dos profissionais em serviço - é de suma importância. Dessa forma potencializa o processo como um todo e, por conseguinte cumpre seu papel fundamental de qualificar o cuidado da população. 


\section{Referências}

ALBIERO J. F. G. Avaliação da Integração EnsinoServiço na Atenção Básica do SUS. 2016. 184 f. Tese. (Doutorado em Saúde Coletiva) - Universidade Federal de Santa Catarina, Florianópolis, 2016.

ALBUQUERQUE V. S. et al. A integração ensino-serviço no contexto dos processos de mudança na formação superior dos profissionais da saúde. Rev. bras. educ. med., Rio de Janeiro, v. 32, n. 3, p. 356-362, 2008.

ANDRADE S. R. et al. Cooperação e relacionamento entre instituições de ensino e serviço de saúde: o Pró-Saúde Enfermagem. Texto Contexto Enferm., Florianópolis, v. 23, n. 1, p. 160-166, 2014.

BATISTA S. H. S. S. et al. Formação em saúde: reflexões a partir dos programas Pró-Saúde e Pet-Saúde. Interface (Botucatu), Botucatu, v. 19, supl. 1, p. 743-752, 2015.

BECCARIA, L. M.; TREVIZAN, M. A.; JANUCCI, M. $Z$. Integração docente-assistencial entre um curso de enfermagem e um hospital de ensino: concepção do processo sob a ótica de docentes, estudantes e enfermeiros. Arq. Ciênc. Saúde, São José do Rio Preto, v. 13, n. 3, p. 61-69, 2006.

BERETTA, I. K.; CALVO, M. C. M.; LACERDA, J. T. Modelo de avaliação da gestão municipal para o planejamento em saúde. Cad. Saúde Pública, Rio de Janeiro, v. 27 , n. 11, p. 2143-2154, 2011.

BRANDÃO, A. L. R. B. S.; GIOVANELLA, L.; CAMPOS, C. E. A. Avaliação da atenção básica pela perspectiva dos usuários: adaptação do instrumento EUROPEP para grandes centros urbanos brasileiros. Ciência \&ł Saúde Coletiva, Rio de Janeiro, v. 18, n. 1, p. 103-114, 2013.

BRASIL. Ministério da Saúde. Diretrizes e Estratégias de Implementação da Política Nacional de Educação

Permanente em Saúde. Brasília, DF: Ministério da Saúde, 2007.

Ministério da Saúde. Política Nacional de Educação Permanente em Saúde. Brasília, DF:
Ministério da Saúde, 2004.

BREHMER, L. C. F.; RAMOS, F. R. S. Experiências de integração ensino-serviço no processo de formação profissional em saúde: revisão integrativa. REE, Goiânia v. 16, n. 1, p. 228-237, 2014.

CAETANO, J. A.; DINIZ, R. C.; SOARES, E. Integração docente-assistencial sob a ótica dos profissionais de saúde. Cogitare Enfermagem, Volta Redonda, v. 14, n. 4, p. 638-644, 2009.

CÂMARA, A. M. C. S. et al. Percepção do Processo Saúde-Doença: significados e valores da educação em saúde. Rev. bras. educ. med., Rio de Janeiro, v. 36, n. 1, p. $10-50,2012$.

CASTRO, R. D.; BRAGA, C. C.; FREIRES, I. A. Integração ensino serviço: experiência exitosa na atenção odontológica à comunidade. Revista Brasileira Ciências da Saúde, Rio de Janeiro, v. 16, n. 1, p. 235-238, 2012.

CAVALHEIRO, M. T. P.; GUIMARÃES, A. L. Formação para o SUS e os desafios da integração ensino serviço. Cadernos do FNEPAS, Brasília, DF, v. 1, 2011.

CECCIM, R. B. Educação Permanente em Saúde: descentralização e disseminação de capacidade pedagógica na saúde. Ciência \& Saúde Coletiva, Rio de Janeiro, v. 10, n. 4, p. 975-986, 2005.

CECCIM, R. B.; FEUERWERKER, L. Mudança na graduação das profissões da saúde sob o eixo da integralidade. Cad. Saúde Pública, Rio de Janeiro, v. 20, n. 5, p. 1400-1410, 2004.

CUNHA P. F.; MAGAJEWSKI, F. Gestão participativa e a valorização dos trabalhadores: avanços no âmbito do SUS. Saúde Soc., São Paulo, v. 21, supl. 1, p.71-79, 2012.

DALMOLIM B. B. et al. Significados do conceito de saúde na perspective de docentes da área da saúde. Esc. Anna Nery, Rio de Janeiro, v. 25, n. 2, p. 389-394, 2011. 
DUSSALT, G. A gestão dos serviços públicos de saúde: características e exigências. Rev. Adm. Pública, Rio de Janeiro, v. 8, n. 2, p. 8-19, 1992.

ELLERY, A. E. L.; BOSI, M. L. M.; LOIOLA, F. A. Integração Ensino, Pesquisa e Serviços em Saúde: antecedentes, estratégias e iniciativas. Saúde Soc., São Paulo, v. 22, n. 1, p. 187-198, 2013.

FERLA. A. A.; FAMER, C. M.; SANTOS, L. M. (Org.). Integração ensino-serviço: caminhos possíveis? Porto Alegre: Editora Rede Unida, 2013.

FERREIRA, J. B. B.; FORSTER, A. C.; SANTOS, J. S. Reconfigurando a Interação entre Ensino, Serviço e Comunidade. Revista Brasileira de Educação Médica, Rio de Janeiro, v. 36, supl. 1, p. 127-133, 2012.

FEUERWERKER, L. C. M.; SENA, R. Contribuição ao movimento de mudança na formação profissional em saúde: uma avaliação das experiências UNI. Interface (Botucatu), Botucatu, v. 6, n. 10, p. 37-50, 2002.

FLORES, L. M. et al. Avaliação do Programa de Educação pelo Trabalho para Saúde - PET-Saúde/ Vigilância em Saúde pelos seus atores. Interface (Botucatu), Botucatu, v. 19, supl. 1, p. 923-930, 2015.

FUENTES, P. S.; GARCIA, M. A. Impacto de un modelo de integración docente asistencial em laformaciónprofesional y el campo clínico. Ciencia y Enfermeria, Concepción, v. 17, n. 3, p. 51-68, 2011.

FURTADO, J. P. Um método construtivista para avaliação em saúde. Ciência \&t Saúde Coletiva, Rio de Janeiro, v. 6, n. 1, p. 165-181, 2001.

GONÇALVES, G. P.; ALBIERO, J. F. G. A participação da fisioterapia na resolubilidade da atenção básica em Blumenau - SC. Revista Extensão em Foco, Palotina, v. 1, n. 7, p. 121-130, 2011

HOLBROOK, W. P. et al. Balancing the role of the dental school in teaching, research, and patient care; including care for underserved areas. European Journal of Dental Education, Copenhagen, v. 1, n. 12, p. 161-166, 2008.
KUABARA, C. T. M. et al. Integração ensino e serviços de saúde: uma revisão integrativa da literatura. REME, Belo Horizonte, v. 18, n. 1, p. 195-201, 2014.

LIMA, P. A. B.; ROZENDO, C. A. Desafios e possibilidades no exercício da preceptoria do Pró-Pet-Saúde. Interface (Botucatu), Botucatu, v. 19, supl. 1, p. 779-791, 2015.

MARIN, M. J. S. et al. A integração ensino-serviço na formação de enfermeiros e médicos: a experiência da FAMEMA. Ciência \&t Saúde Coletiva, Rio de Janeiro, v. 19, n. 3, p. 967-974, 2014.

MARSIGLIA, R. G. Relação ensino/serviços: dez anos de integração docente assistencial (IDA) no Brasil. São Paulo: Hucitec; 1995.

MENDÉZ, S. Influencia de laintegración docente asistencial em lacalidad de losserviciosdel primer nivel Del Perú y em laformación médica. 2012. 227 f. Tese (Doutorado em Medicina) - Facultad de Medicina, Universidad Nacional Mayor de San Marcos, Lima, 2012.

MOIMAZ, S. A. S.; MARQUES, J. A. M.; SALIBA, O. Satisfação e percepção do usuário do SUS sobre o serviço público de saúde. Physis, Rio de Janeiro, v. 20, n. 4, p. 1419-1440, 2010.

NUNES, E. D. Interdisciplinaridade: conjugar saberes. Saúde em Debate, Rio de Janeiro, v. 26, n. 62, p. 249-258, 2002.

OLSCHOWSKY, A.; SILVA, G. B. Integração docente-assistencial: um estudo de caso. Rev Esc Enferm USP., São Paulo, v. 34, n. 2, p. 128-137, 2000.

PAIM, J. S. O quê é SUS? Rio de Janeiro: Fiocruz, 2009. (Coleção Temas em Saúde).

PEREIRA, A. F. Integração ensino-serviço em Porto Alegre: a construção do distrito docente assistencial Glória-Cruzeiro-Cristal. 2013. 60 f. Monografia (Especialização em Saúde Coletiva) - Escola de Saúde Pública do Rio Grande do Sul, Porto Alegre, 2013. 
PEREIRA, J. G.; FRACOLLI, L. A. Articulação ensino-serviço e vigilância da saúde: a percepção de trabalhadores de saúde de um distrito escola. Trab. educ. saúde (Online), Rio de Janeiro, v. 9, n. 1, p. 63-75, 2011.

PIZZINATO, A. et al. A Integração Ensino-Serviço como Estratégia na Formação Profissional para o SUS. Rev. bras. educ. med., Rio de Janeiro, v. 36, supl. 2, p. 170-177, 2012.

QUEIROZ, M. F. F. et al. Grupo PET-Saúde/Vigilância em Saúde ao Trabalhador Portuário: Vicência compartilhada. Interface (Botucatu), Botucatu, v. 19, supl. 1, p. 941-951, 2015.

REIBNITZ, K. S. et al. Rede Docente Assistencial UFSC/SMS de Florianópolis: Reflexos da Inplantação dos Projetos PróSaúde I e II. Rev. bras. educ. med., Rio de Janeiro, v. 36, n. 1, p. 68-75, 2012.

RIBEIRO, I. L. Aprendizagem na interação ensino-serviço-comunidade: a formação na perspectiva dialógica da sociedade. 2013. 150 f. Dissertação (Mestrado em Saúde Coletiva) - Universidade Federal do Rio Grande do Norte, Natal, 2013.

SANDER B. Gestão da educação na América Latina: construção e reconstrução do conhecimento. Campinas: Autores associados, 1995.
SCARATTI, D.; CALVO, M. C. M. Indicador sintético para avaliar a qualidade da gestão municipal da atenção básica a saúde. Rev. Saúde Públ., São Paulo, v. 46, n. 3, p. 446-455, 2012.

SORDI, M. R. L. et al. O potencial da avaliação formativa nos processos de mudança da formação dos profissionais da saúde. Interface (Botucatu), Botucatu, v. 19, supl. 1, p. 731-742, 2015.

SOUZA, A. L.; CARCERERI, D. L. Estudo qualitativo da integração ensino serviço em um curso de graduação em odontologia. Interface (Botucatu), Botucatu, v.15, n. 39, p. 1071-1084, 2011.

TOMBINI, L. H. T. Educação permanente e integração ensino-serviço na perspectiva dos enfermeiros do serviço. 2010. 177 f. Dissertação (Mestrado em Enfermagem) Universidade Federal de Santa Catarina, Florianópolis, 2010.

VIEIRA, S. P. et al. Planos de carreira, cargos e salários no âmbito do Sistema Único de Saúde: além dos limites e testando possibilidades. Saúde em Debate, Rio de Janeiro, v. 41, n. 112, p. 110-121, 2017.

Recebido para publicação em março de 2017

Versão final em junho de 2017

Conflito de interesses: inexistente

Suporte financeiro: não houve 